
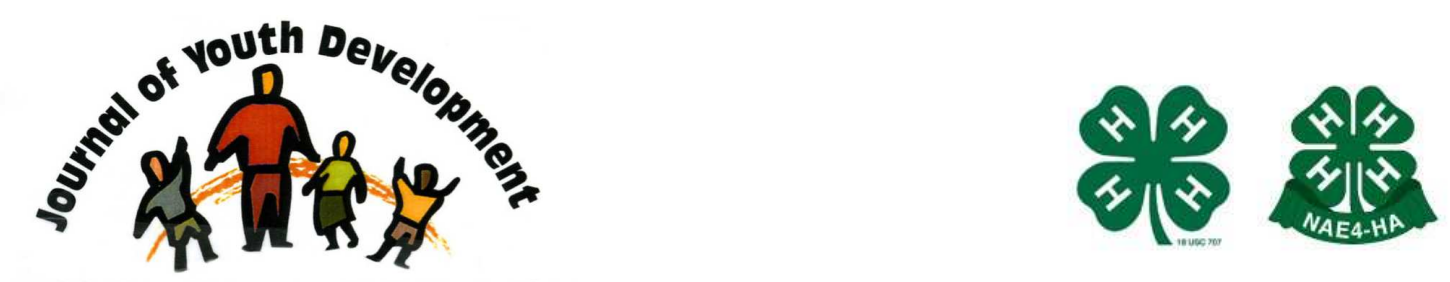

Bridging Research \& Practice

\title{
Intentional Self Regulation and Positive Youth Development: Implications for Youth Development Programs
}

\author{
Lisa M. Chauveron \\ Montclair State University \\ chauveronl1@mail.montclair.edu
}

Miriam R. Linver and Jennifer Brown Urban

Montclair State University 


\title{
JOURNAL OF YOUTH DEVELOPMENT \\ bridging research and practice

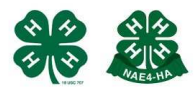

Volume 10, Number 3, Special Issue 2015

Article 151003FA007

\section{Intentional Self Regulation and Positive Youth Development: Implications for Youth Development Programs}

Lisa M. Chauveron, Miriam R. Linver and Jennifer Brown Urban Montclair State University

\begin{abstract}
Character education programs are mission-aligned with the positive youth development (PYD) perspective, which, in research with American youth suggests that intentional selfregulation (ISR) develops through mutually beneficial interactions between youth and their environment. Cross-cultural studies of Western youth suggest an adolescence-specific ISR process may exist. We begin to extend this work to assess the relationship between ISR and positive development in young Scottish adolescents (approximately 7th grade, $N=82 ; 50 \%$ male), a previously unexamined group. ISR was correlated with the Five Cs of PYD and OLS regression analyses demonstrated that ISR predicted two of the Five Cs: Character and Connection. We discuss implications for youth development programs of the findings that ISR and some indices of PYD were linked in a sample of Scottish youth.
\end{abstract}

\section{Introduction}

All civil societies share a common interest in promoting the development of responsible, global citizens (Althof \& Berkowitz, 2006). Strategies to mold youth into healthy societal contributors have been present in youth-focused ecologies since the inception of schooling (White \& Warfa, 2011). Programs cultivating character are mission-aligned with positive youth development (PYD), a strengths-based approach to optimizing the potential within all youth for positive developmental outcomes by fostering pro-social experiences between youth, peers and adults in school and community environments (Lerner et al., 2005). Research with American youth suggests that one aspect of individual development influenced by PYD programs is intentional self regulation (ISR) as youth set and reach goals in contexts with positive options (Gestsdottir \& Lerner, 2007, 2008). This work has been extended internationally, examining the link between ISR and PYD in four countries: Canada, Germany, Iceland, and the U.S. (Gestsdottir et 
al., 2015). The current investigation is a preliminary assessment, which begins to examine if ISR is related to positive development in young Scottish adolescents. Based on our findings about this relation, we discuss implications for youth development programs, ones that might help bridge the gap between theory and practice both domestically and internationally.

\section{The Positive Youth Development (PYD) Perspective}

The PYD perspective emphasizes that all youth have the potential for healthy, successful development (Lerner, Dowling, \& Anderson, 2003; Little, 1993). Instead of conceptualizing youth as problems to be managed, it posits that they are resources to be developed (Roth \& Brooks-Gunn, 2003a, 2003b). Youth development programs may build skills in an array of areas through engaging youth in activities such as the performing arts, sports, and volunteerism during out-of-school time in community or educational spaces (Chauveron, Perkins, \& Borden, 2004; Vandell, Larson, Mahoney \& Watts, 2015). Several concepts are involved in the PYD perspective. First, PYD is promoted in supportive environments; such settings provide developmentally appropriate activities and community connections that may generate positive growth (Lerner, Lerner \& Benson, 2011). The key idea in the PYD perspective is that, when individual strengths are aligned with contextual resources for healthy development systematically over time, youth thrive (Lerner, Lerner, Bowers, \& Geldhof, 2015); that is, they develop cognitive and behavioral competence, confidence, positive social connections, strong character, and caring or compassion (Hamilton, Hamilton, \& Pittman, 2004; King et al., 2005).

Second, in regard to contextual resources or ecological assets, the PYD perspective endorses the benefits of community-based programming with opportunities for youth to build sustained relationships with positive, supportive peers and adults through activity participation. Third, and in regard to the strengths of youth, the PYD perspective, capitalizes on the plasticity of developmental change ubiquitous during adolescence (Lerner, et al., 2015), and promotes the idea that youth should have active roles in program selection and development; rather than act as unempowered service recipients (Hamilton et al., 2004), youth should be encouraged to act as leaders whose voices are valued (Urban, 2008).

Here, ISR enters into the perspective as a key instance of youth strengths. ISR involves skills such as goal selection and management, using strategic thinking, executive functioning, or resource recruitment to optimize the chances of attaining one's goals, and compensating effectively when goals are blocked or when optimization attempts fail, for example, see the discussion of selection, optimization and compensation, or SOC, in the ISR literature associated with the work of Baltes and colleagues (e.g., Baltes \& Baltes, 1990; Baltes, Lindenberger, \& Staudinger, 2006; Freund \& Baltes, 2002; in addition, see Gestdottir \& Lerner, 2008, and McClelland, Geldhof, Cameron, \& Wanless, 2015, for reviews). Finally, based on the ideas of plasticity, youth strengths, and ecological assets, the PYD perspective takes an optimistic view about the possibility of promoting greater levels of thriving among all youth; that is, with sufficient structure and opportunities, youth can build on their strengths to overcome risk factors and successfully negotiate the transition to adulthood (Roth \& Brooks-Gunn, 2003a).

As implied above, one widely accepted taxonomy of PYD attributes, the Five Cs (Lerner et al., 2015; Little, 1993), offers a categorization of PYD outcomes, including: (1) competence in academic, social, and vocational areas; (2) confidence or positive self-identity; (3) connection to community, family, and peers; (4) character or positive values and moral commitment; and (5) caring and compassion (Lerner, Fisher, \& Weinberg, 2000). Empirically, each of the Five Cs of PYD is a distinct component of positive youth development in young adolescents (e.g., Gestsdottir \& Lerner, 2007; Lerner et al., 2015). 
In turn, there is evidence that as early as 5th grade in the U.S., ISR (as indexed by measures of selection, optimization, and compensation associated with the above-noted SOC model) is related to the CS of PYD (Gestsdottir \& Lerner, 2007; Lerner et al., 2005). In turn, these studies also found that these ISR/SOC-related scores are negatively associated with increased risk behaviors including depression, substance abuse, and delinquency. Findings from this U.S. sample showed that when the specific combination of youth ISR skills are coupled with a supportive, nurturing environment, positive development is optimized. Subsequent research found that youth who score higher on ISR (SOC) measures are more likely to seek and use helpful resources in their ecology (Urban, Lewin-Bizan \& Lerner, 2010).

In short, in adolescence, youth with strong ISR skills are equipped to conceive more options to solve problems, reflect on past decisions to guide future choices, and deal with adversity (Trommsdorff, 2012). These attributes are all keys to successful developmental trajectories (Lerner \& Gestsdottir, 2007).Some evidence suggests ISR processes are linked to adolescents developing in nations other than the U.S., although ISR development and functioning may nevertheless vary across cultural contexts (Gestsdottir et al., 2015). Recent research with more than 4,000 adolescents in Canada, Germany, Iceland, and the U.S., found no evidence for a tripartite model of SOC, where Selection, Optimization and Compensation are distinct aspects of the ISR process. Instead, evidence was found for a global ISR structure (wherein selection, optimization, and compensation were undifferentiated). Thus, for adolescents from the U.S. and at least three other Western nations, ISR might best be represented as one "adolescencespecific" construct, whereas for adults it is best represented as a three-part process (Baltes, Lindenberger, \& Staudinger, 2006). As research on ISR functioning in adolescence continues in new geographic contexts, research in additional countries is needed; to date, ISR has not yet been examined in Scottish youth.

\section{The Present Study}

Accordingly, the present study extends previous work to assess the relationship between ISR and PYD in young Scottish adolescents in their second year of secondary school (called S2, approximately $7^{\text {th }}$ grade in the U.S.). Our aim was to provide a preliminary foray into ISR work in Scotland in order to contribute to growing knowledge of self-regulation and, possibly as well, to understand how promoting ISR among Scottish youth might enhance opportunities to support positive development in this nation. As such, the research we report is part of a larger effort that aspires to deepen scholarly and practitioner work about the process of adolescencespecific ISR and its relationship to PYD in a heretofore unstudied sample of adolescents. The present report is an initial one, however, and offers only a preliminary assessment of ISR functioning and its connection to PYD in Scottish youth.

Baseline assessments of ISR and PYD were assessed in the context of a process evaluation of the school-based Inspire>Aspire: Global Citizens in the Making (I>A) program, a character education program that creates educational experiences for youth that foster the values of honesty, generosity, reliability, future mindedness, diligence, thrift, joy, purpose, curiosity, and humility. I>A encourages certified teachers to select web-based activities or create tailored options promoting self-discovery and community building, through varying implementation models culminating in a themed poster. Using the international work of Gestsdottir et al. (2015) as a guide, the present study focused on the following research question: Among Scottish youth, is ISR (as indexed by a measure associated with the SOC model; Freund \& Baltes, 2002) associated with PYD (defined as the Five Cs of PYD)? 


\section{Method}

\section{Participants}

Data from the current study were derived from a subset of participants from the baseline of the I $>$ A process evaluation, a 2-wave, 1-year study to evaluate implementation strategies and pilot test program outcome measures (Linver, Urban, Chauveron et al., May, 2015). Pupils had not yet participated in the I>A program when data for the current study were collected; thus, only the first wave of data was available for the present report. Surveys were completed in six classes (two classes each in three schools) in townships in Scotland concentrated in the north of the country. We used data from 82 S2 (i.e., the equivalent of U.S. $7^{\text {th }}$ grade) student respondents who had completed surveys; data collection for the larger evaluation continued beyond the cut-off date for inclusion in the present study. About $98 \%$ of participants identified their racial/ethnic background as White. All youth attended schools in their neighborhoods, and all schools served youth from relatively high SES backgrounds, with relatively low rates of "income deprived" residents (about 7\% compared to 13\% in Scotland overall; National Records of Scotland, 2011 Census). The mean age was 12.96 years $(S D=.37)$. Gender was evenly represented between males (50\%) and females (50\%).

\section{Measures and Procedure}

The present study assessed demographic characteristics, as well as ISR (through SOC) and the Five Cs of PYD. These assessments are described in detail below.

Survey administration. A project coordinator worked with schools and teachers to distribute and secure consent and assent forms. Soon thereafter, teachers administered surveys to pupils during one class session. Teachers were available to clarify questions if needed.

Demographic characteristics. Pupils self-reported their age, gender, race/ethnicity, home composition, and parent education. Child age was coded in months, whereas child gender was coded as male (0) and female (1). Race/ethnicity was ascertained using a question adapted from the Scottish National Census to describe White, Asian, African, Caribbean or Black, or other options ("Scotland's New Official Ethnicity Classification," 2008). Pupils were able to select singular or multiple answers to reflect their racial/ethnic identity. Each pupil selected from categories of parental marital status including married, separated or divorced; these responses were collapsed into two categories: married $(1 ; 73 \%)$ and not married $(0 ; 27 \%)$.

Intentional self-regulation. ISR was assessed using the same version of the SOC measure as used by Gestsdottir and colleagues (2015). S (Selection) includes goals, O (Optimization) involves steps to achieve said goals, and $\mathrm{C}$ (Compensation) includes adjustments to challenges and barriers to maintain success in goal attainment (Baltes, Lindenberger, \& Staudinger, 2006). Gestsdottir, et al. reported that, to create the SOC measure they employed, nine items were taken from the 24-item SOC measure (Freund \& Baltes, 2002; Gestsdottir, Bowers, von Eye, Napolitano, \& Lerner 2010). Items from three subscales (two from S, four from O, and three from C) comprise the abbreviated version of SOC (Cronbach's $a=.65$ with the present sample). Participants were asked to respond to one of two options asking which type of person they are more like, Person A or B. One response was consistent with using SOC skills whereas the other response choice was inconsistent with using SOC skills. SOC-consistent responses were scored as 1 and non-SOC-consistent responses were scored as 0; all items were summed to create the abbreviated SOC scale score. 
Positive Youth Development. PYD was assessed in regard to the Five Cs using the PYD-Very Short Form (PYD-VSF; see Geldhof et al., 2014). Sixteen of the 17 items were used; one item in the Character subscale was replaced with a similar question in a process described below. The PYD-VSF includes three items each for the subscales of Caring, Competence and Confidence, and four items each for the Character, and Connection subscales. All items use five-point Likert response options, with higher scores reflecting higher levels of the construct. Caring items measure this construct globally. Connection items assess relationships with neighborhood, family, school, and peers, and Competence items index academic, social, and physical facets of this construct. Confidence items index self-worth, positive identity, and physical appearance. Character items assess support for diversity, performance, and personal values; however, a conduct behavior item asks respondents to select which of two statements is most true for them. To address social conscience in the Character subscale, an item from the Revised Stanford Youth Purpose scale (Bundick et al, 2006; Steger et al., 2006) was included using a Likert-scale ranging from 0 to 6 to index agreement from strongly disagree to strongly agree.

Items were recoded to ensure each was allotted equal weight, including the proxy Character item. For analyses, this item was transposed from a 6-point scale to a 5-point scale to match the other items. Higher scores on all items reflect higher amounts of each $\mathrm{C}$. In the present sample, the overall PYD-VSF had acceptable reliability (Cronbach's $a=.74)$. However, reliability varied for the subscales: Caring (Cronbach's $a=.78)$, Connection (Cronbach's $a=.78$ ), Confidence (Cronbach's a=.76), Character (Cronbach's a=.61), and Competence (Cronbach's $a=.50)$.

Missing Data. The SOC measure had virtually no missing data, while the PYD-VSF had less than $10 \%$ missing. Missing data were imputed with multiple imputation (Jelicic, Bobek, Phelps, Lerner, \& Lerner, 2009). Our approach here used available data to determine response patterns and to then create a pooled summary of five probable iterations to replace it. The multiple imputation feature in SPSS was used to complete the process. Pooled data from the imputation process were markedly similar to the original data and thus we used the original data set. However, imputed descriptive statistics are available from the authors upon request.

\section{Results}

Preliminary analyses. As a first step, a univariate matrix involving Pearson product-moment correlations was computed using the imputed data to examine the relationships among SOC scores, each of the Five Cs, and pupil demographic characteristics. Child gender and parent marital status were correlated with the SOC score and with each of the Five Cs (see Table 1). As indicated in the table, having married parents was significantly associated with higher Confidence and Connection. Gender was significantly associated with four of the five Cs, with boys having higher Competence and Confidence, whereas girls had higher Character and Caring. There were no gender differences in regard to Caring or the SOC scores. Most correlations among the Cs were significant and positive, as were the correlations among the Cs and SOC. These findings suggest that the connections between ISR and PYD may exist among Scottish youth in the same ways in which they exist among youth from other Western nations. However, two correlations among the Cs were significant and negative; that is, between Competence and Character, and Competence and Caring. Although both correlations are low and therefore account for very small proportions of the variance $(0.02 \%$ and $0.03 \%$, respectively), their presence in this data set indicates that either PYD may have a different meaning in Scotland than in the U.S. and/or that the PYD-VSF is not measuring PYD in the same way in both settings. 
Table 1

Correlations among scores for the Five CS of PYD, SOC, and pupil demographic characteristics.

\begin{tabular}{|l|c|c|c|c|c|c|c|c|}
\hline & 1 & 2 & 3 & 4 & 5 & 6 & 7 & 8 \\
\hline 1. Competence & -- & & & & & & & \\
\hline 2. Caring & $-.166^{* *}$ & -- & & & & & & \\
\hline 3. Connection & $.299^{*}$ & $.099^{*}$ & -- & & & & & \\
\hline 4. Confidence & $.395^{* *}$ & -.063 & $.401^{* *}$ & -- & & & & \\
\hline 5. Character & $-.139 * *$ & $.546^{* *}$ & $.149 * *$ & .071 & -- & & & \\
\hline 6. SOC & $.144^{* *}$ & $.099^{*}$ & $.345^{* *}$ & $.237^{* *}$ & $.307^{* *}$ & -- & & \\
\hline 7. Gender & $-.178^{* *}$ & $.406^{* *}$ & .014 & $-.297^{* *}$ & $.204^{* *}$ & -.061 & -- & \\
\hline 8. Parent marital status & -.088 & .001 & $.134^{* *}$ & $.144^{* *}$ & .084 & .088 & .080 & -- \\
\hline Note: $* \mathrm{p}<.05 . * \mathrm{p}<.01$. & & & & & \\
\hline
\end{tabular}

Regression analyses. Hierarchical OLS regression analyses in two steps were conducted to assess if ISR predicted PYD. In the first step, gender and parental marital status were entered as controls, based on univariate analyses suggesting connections between these demographic analyses, and scores for the Five Cs and SOC. Other demographic characteristics did not demonstrate these associations, and were therefore not included in the control model. In the second step, the relationship between SOC and the Five Cs scores were assessed. Results demonstrated that SOC scores predicted two of the Five Cs: Connection and Character, when controlling for background characteristics. Pooled estimates of results from the second step of the regression predicting Character demonstrated $R^{2}$ change $=.10(F[1,78]=9.207, p<.05)$ and for Connection $R^{2}$ change $=.12(F[1,78]=10.327, p<.05)$. Thus, ISR, as indexed by the nine-item global SOC measure (Gestsdottir, et al., 2015), was found to predict two of the Cs in young Scottish adolescents in a manner consistent with prior research with other Western adolescents. However, since SOC scores did not significantly predict the other Cs, there are also differences between the present sample of Scottish youth and other Western adolescents (e.g., Gestsdottir et al., 2015).

\section{Discussion}

Societies share a common interest in promoting the development of thriving, contributing citizens. To flourish, citizens must demonstrate good character, social-emotional competence, and a moral commitment to improving both their own well-being as well as that of their communities. PYD programs aim to encourage those very qualities in developing youth. In part, PYD programs facilitate positive development by presenting beneficial environmental resources to supplement existing options. Doing so increases opportunities for "good fit" between youth and their environment. Furthermore, additional caring adults, engaging activities, and youthfocused spaces can support positive outcomes and goal attainment in youth. The current study demonstrated that ISR was associated with PYD among young Scottish adolescents. Although there are some discrepancies between the present sample of Scottish youth and adolescents in other investigations of Western youth, the general nature of the present findings are consistent with those of Gestsdottir and colleagues (2015), whose work suggests that a global measure of ISR (based on the SOC model; Baltes, et al., 2006; Freund \& Baltes, 2002) is generalizable across samples of youth from Western countries. 
The preliminary analyses of data from the I>A project that were presented in this article indicated that SOC scores were associated with each of the Five Cs of PYD, albeit not in precisely the same ways as in past research with youth from other Western nations (e.g., Gestsdottir \& Lerner, 2007). For instance, although zero-order correlations between SOC scores and each of the five Cs were all positive and significant, the results of regression analyses controlling for gender and parental marital status indicated that SOC scores predicted only Character and Connection scores. In addition, the zero-order correlational analyses indicated inverse (albeit quite small) relations among some of the Cs. These findings may involve either a somewhat different latent meaning of PYD among Scottish youth and/or the need for a different measure of PYD among these adolescents (that is, the PYD-VSF may work differently in samples of Scottish youth than in sample of U.S. youth). Nevertheless, it is also the case that the present findings suggest that the 9-item SOC measure may be useful in future studies with Scottish youth during the early adolescent period.

The zero-order correlations between the SOC scores and the individual Cs also suggest that research and practice may choose to focus on specific components of PYD. The regression findings suggest that Character (measured as positive values and moral commitment) and Competence (measured in academic, social, and vocational areas) may be more related to SOC. Findings could also mean the other Cs are not as salient in cultural settings different than those in the U.S. In short, whereas our sample was small and relatively homogenous, it is possible that these findings could also be suggesting opportunities for emphases in Scottish PYD programs for young adolescents or a need to revisit the social construction of the Five Cs in a Scottish context. The field would further benefit from qualitative investigations on this matter.

In their investigation of adolescent ISR (indexed through the SOC measure used also in the present research) in four Western countries, Gestsdottir and colleagues (2015) found that individual items on the 9-item SOC measure showed contrasting levels of variation among different age groups, both within and across nations. Perhaps future waves of data collection with the youth studied in the I>A project will also reveal such age-associated variation. Moreover, some items excluded from the original 24-item SOC measure in order to form the 9item measure may be salient among young Scottish adolescents. Item phrasing may need adjustment as well, as Gestsdottir and colleagues (2015) found that Canadian participants found reverse-coded items difficult to understand. Finally, the 24-item SOC itself may need to be tested in Scottish contexts for use with adolescents generally, as the tool was initially created for use with American adults. Together, both the findings of the present research and the points we have made regarding issues that need to be addressed in future research have implications for theory-predicated applications to practice and to narrowing what we believe is a still too wide gap between research and the conduct of youth development programs.

That is, we believe that theory and practice are necessarily intertwined in successful efforts to promote healthy development in adolescence. The connections between ISR and PYD mean that having a context-specific (i.e., national- and developmental level-specific), research-based understanding of ISR is essential if youth development program practitioners seek to create skill-building strategies that will eventuate in PYD.

\section{Practice Implications}

By testing the relationship between ISR and PYD, we found that a zero-order relationship existed for measures of these constructs and, in regression analyses, that ISR predicted in particular Connection and Character when gender and parental marital status were controlled. 
It may be possible that young Scottish adolescents have more opportunity to practice ISR behaviors, such as planfulness and goal-setting, in regard to Character and Connection. For example, the Scottish public school system incorporates a class on religion and moral ethics, perhaps providing youth with different exposure to or emphasis on those concepts than is the case for American youth in public schools. The gender differences associated with the Competence and Confidence relation, favoring boys, and the Character and Caring relation, favoring girls, may indicate focal areas for program curriculum efforts aimed at narrowing these gender differences.

Overall, for practitioners to promote the Five Cs in general, they should focus on enhancing adolescent self-regulation skills (Napolitano et al., 2014). To promote PYD, schools and communities should encourage youth to regularly spend out-of-school time in multiple youth development programs, such as performing and visual arts, sports, volunteerism, student government or technology. Research shows that such programs represent important developmental assets (Vandell, Larson, Mahoney \& Watts, 2015) and that participation with more than one activity can buffer youth from negative experiences with other people or contexts (Eccles \& Gootman, 2002; Zarrett, et al. 2009). However, data also suggest impacts diminish when youth are overscheduled by regularly participating in more than four activities (Mahoney, Harris \& Eccles, 2008). As such, practitioners need to consult research to learn that the tipping point is between asset and liability in their specific settings and, in turn, researchers need to study these setting to identify these tipping points.

To encourage ISR skill-building, youth workers should create opportunities for building ISR skills. Recent programs for such development have shown success in U.S. contexts (Bowers, et al., in press; Napolitano, et al., 2014). However, such work needs to be extended cross nationally, especially given the context-specific relations between ISR-and PYD that were illustrated by the present findings. This work should enable practitioners to pay sufficient attention to and repetition of the process of setting and attaining goals. Professional development or collaborative adult work may prove beneficial to select an approach and implementation plan appropriate for a specific setting.

\section{Conclusions: Limitations and Future Directions}

This research was of course limited by the use of a select sample of Scottish youth assessed at only one point in time with measures developed for youth living in other nations. Nevertheless, the findings of this research showed both some similarities to and discrepancies with prior research using the same measures with youth from several other Western nations. As such, the results underscore the truism that, in some respects, all youth share some common attributes and, as well, some group-specific characteristics (in addition, all youth have facets of individual distinctiveness). Thus, and despite the fact that we generated the present findings from preliminary data from the I>A project, we have been able to suggest some implications of the present results from the design and implementation of youth development programs.

However, because research about the ISR-PYD relation, especially from a cross-national perspective, is still relatively new, theory-predicated research and more evaluation of theorypredicated programs is warranted. To provide maximum benefits to youth, continued conversations between researchers and practitioners are necessary. Members of both groups must act, therefore, as partners, mission-aligned in work and passion. 


\section{References}

Althof, W., \& Berkowitz, M.W. (2006). Moral education and character education: Their relationship and roles in citizenship education. Journal of Moral Education, 35(4), 495-518.

Baltes, P.B., \& Baltes, M.M. (1990). Psychological perspectives on successful aging: The model of selective optimization with compensation. In P.B. Baltes \& M.M. Baltes. (Eds.), Successful aging: Perspectives from the behavioral sciences (pp. 1-34). New York: Cambridge University Press.

Baltes, P.B., Lindenberger, U., \& Staudinger, U.M. (2006). Life span theory in developmental psychology. In R.M. Lerner (Ed.), Theoretical models of human development. Handbook of child psychology (6th ed., Vol. 1, pp. 569-664). Hoboken, NJ: Wiley.

Brandtstädter, J. (1998). Action perspectives on human development. In W. Damon, \& R.M. Lerner (Eds.), Theoretical models of human development. Handbook of child psychology. (5 ${ }^{\text {th }}$ ed., Vol. 1, pp. 807-863).

Bowers, E.P., Wang, J., Tirrell, J.M., \& Lerner, R.M. (In press). The role of mentor-mentee relationships in the development of intentional self-regulation among adolescents. Journal of Community Psychology.

Bundick, M.J., Andrews, M.C., Jones, A., Moran, S., Mariano, J.M., Bronk, K.C., \& Damon, W. (2008). Youth Purpose Survey Version 2008. Unpublished instrument, Stanford Center on Adolescence, Stanford, CA.

Chauveron, L.M., Perkins, D.F. \& Borden, L. (2004). Community youth development: Beyond youth development. In C.B. Fisher, \& Lerner, R. M. (Eds.), Encyclopedia of Applied Developmental Science. Thousand Oaks: Sage.

Freund, A.M., \& Baltes, P.B. (2002). Life-management strategies of selection, optimization and compensation: Measurement by self-report and construct validity. Journal of Personality and Social Psychology, 82(4), 642-662.

Geldhof, G., Bowers, E., Mueller, M., Napolitano, C., Callina, K., \& Lerner, R. (2014). Longitudinal analysis of a very short measure of positive youth development. Journal of Youth \& Adolescence, 43(6), 933-949.

Gestsdottir, S., Bowers, E., von Eye, A., Napolitano, C.M., \& Lerner, R.M. (2010). Intentional Self-regulation in middle adolescence: The emerging role of loss-based selection in positive youth development. Journal of Youth and Adolescence, 39(7), 764-782.

Gestsdottir, S., Geldhof, G.J., Paus, T., Freund, A., Adalbjarnardottir, S., Lerner, J.V., \& Lerner, R.M. (2015). Self-regulation among youth in four Western cultures: Is there an adolescencespecific structure of the Selection-Optimization-Compensation (SOC) model? International Journal of Behavioral Development, 39(2), 171-185.

Gestsdottir , S., \& Lerner, R.M. (2007). Intentional self-regulation and positive youth development in early adolescence: Findings from the 4-H Study of Positive Youth Development. Developmental Psychology, 43(2), 508-224. 
Gestsdottir , S., \& Lerner, R.M. (2008). Positive development in adolescence: The development and role of intentional self-regulation. Human Development, 51(3), 202-224.

Hamilton, S.F., Hamilton, M.A., \& Pittman, K. (2004). Principles for youth development. In S. F. Hamilton \& M.A. Hamilton (Eds.), The youth development handbook: Coming of age in American communities (pp. 3-22). Thousand Oaks, CA: Sage Publications.

Jelicic, H., Bobek, D., Phelps, E.D., Lerner, J.V., \& Lerner, R.M. (2007). Using positive youth development to predict contribution and risk behaviors in early adolescence: Findings from the first two waves of the 4-H Study of Positive Youth Development. International Journal of Behavioral Development, 31(3), 263-273.

King, P., Dowling, E.M., Meuller, R.A., White, K., Schultz, W., \& Osborn, P., et al. (2005). Thriving in adolescence: The voices of youth-serving practitioners, parents, and early and later adolescents. Journal of Early Adolescence, 25(94-112).

Lerner, R.M. (2006). Developmental science, developmental systems, and contemporary theories of human development. In R.M. Lerner \& W. Damon (Eds.), Handbook of Child Psychology: Theoretical models of human development (6th ed., Vol. 1, pp. 1-17). Hoboken, NJ: John Wiley \& Sons.

Lerner, R.M., Dowling, E.M., \& Anderson, P.M. (2003). Positive youth development: Thriving as the basis of personhood and civil society. Applied Developmental Science, 73 , 172-180.

Lerner, R.M., Fisher, C.B., \& Weinberg, R.A. (2000). Toward a science for and of the people: Promoting civil society through the application of developmental science. Child Development, 71(11-20).

Lerner, R.M., Lerner, J.V., Almerigi, J., Theokas, C., Phelps, E., Gestsdottir , S., . . . von Eye, A. (2005). Positive youth development, participation in community youth development programs, and community contributions of fifth grade adolescents: Findings from the first wave of the 4-H Study of Positive Youth Development. Journal of Early Adolescence, $25(1), 17-71$.

Lerner, R.M., Lerner, J.V., Bowers, J.G., \& Geldhof, G.J. (2015). Positive Youth Development: A relational systems model. In R. M. Lerner (Ed.), Handbook of Child Psychology and Developmental Science (7th ed., Vol. 1, pp. 608-651). Hoboken, NJ: John Wiley \& Sons.

Lerner, J.V., Phelps, E., Forman, Y., \& Bowers, E.P. (2009). Positive youth development. In R. M. Lerner \& L. Steinberg (Eds.), Handbook of adolescent psychology (3rd ed., Vol. 1, pp. 524-558). Hoboken, NJ, US: John Wiley \& Sons Inc.

Linver, M.R., Urban, J.B., Chauveron, L.M., Barrios, V., Illnick, V., Gama, L., \& Jensen, R., MacDonnell, M. (2015, May). Is early adolescent self-regulation associated with the 5 Cs of Positive Youth Development? Findings from Scottish youth. Poster presented at the annual meeting of the Association of Psychological Science, New York, NY. 
Little, R.R. (1993). What's working for today's youth: The issues, the programs, and the learnings. Paper presented at the Institute for Children, Youth, and Families Fellows' Colloquium, Michigan State University.

McClelland, M.M., Geldhof, G.J., Cameron, C.E., \& Wanless, S B. (2015). Development and self-regulation. In R. M. Lerner (Ed.), Handbook of Child Psychology and Developmental Science (7th ed., Vol. 1, pp. 1-43). Hoboken, NJ: John Wiley \& Sons.

Napolitano, C.M., Bowers, E.P., Gestsdottir, S., Depping, M., von Eye, A., Chase, P., \& Lerner, J.V. (2011). The role of parenting and goal selection in positive youth development: A personcentered approach. Journal of Adolescence, 34, 1137-1149.

Napolitano, C.M., Bowers, E.P., Arbeit, M.R., Chase, P., Geldhof, G.J., Lerner, J.V., \& Lerner, R.M. (2014). The GPS to Success Growth Grids: Measurement properties of a tool to promote intentional self-regulation in mentoring programs. Applied Developmental Science, 18(1), 46-58.

National Records of Scotland, 2011 Census: Aggregate data (Scotland) [computer file]. UK Data Service Census Support. Downloaded from: http://infuse.mimas.ac.uk. Retrieved August 10, 2015.

Roth, J.L., \& Brooks-Gunn, J. (2000). What do adolescents need for healthy development?: Implications for youth policy. Society for Research in Child Development Social Policy Report, 14(1), 3-19.

Roth, J.L., \& Brooks-Gunn, J. (2003a). What exactly is a youth development program? Answers from research and practice. Applied Developmental Science, 72 , , 94-111.

Roth, J.L., \& Brooks-Gunn, J. (2003b). Youth development programs: Risk, prevention, and policy. Journal of Adolescent Health, 32(3), 170-182.

Roth, J.L., Brooks-Gunn, J., Murray, L., \& Foster, W. (1998). Promoting healthy adolescents: Synthesis of youth development program evaluations. Journal of Research on Adolescence, $8(4), 423-459$.

Steger, M.F., Frazier, P., Oishi, S., \& Kaler, M. (2006). The Meaning in Life Questionnaire: Assessing the presence of and search for meaning in life. Journal of Counseling Psychology, 53, 83-93.

Trommsdorff, G. (2012). Development of "agentic" regulation in cultural context: the role of self and world views. Child Development Perspectives, 6(1), 19-26.

Urban, J.B. (2008). Components and characteristics of youth development programs: The voices of youth-serving policy makers, practitioners, researchers, and adolescents. Applied Developmental Science, 12(3), 128-139.

Urban, J. B., Lewin-Bizan, S., \& Lerner, R.M. (2010). The role of intentional self-regulation, lower neighborhood ecological assets, and activity involvement in youth developmental outcomes. Journal of Youth and Adolescence, 39(7), 783-800. 
Vandell, D.L., Larson, R.W., Mahoney, J.L., \& Watts, T.W. (2015). Children's organized activities. In R.M. Lerner (Ed.), Handbook of Child Psychology and Developmental Science (7th ed., Vol. 4, pp. 1-45). Hoboken, NJ: John Wiley \& Sons.

White, R. \& Warfa, N. (2011), Building schools of character: A case-study investigation of character education's impact on school climate, pupil behavior, and curriculum delivery. Journal of Applied Social Psychology, 41, 45-60.

Zarrett, N., Fay, K., Carrano, J., Li, Y., Phelps, E., \& Lerner, R.M. (2009). More than child's play: Variable- and pattern-centered approaches for examining effects of sports participation on youth development. Developmental Psychology. 45(2), 368-382.

(C) Copyright of Journal of Youth Development Bridging Research and Practice. Content may not be copied or emailed to multiple sites or posted to a listserv without copyright holder's express written permission. Contact Editor at: patricia.dawson@oregonstate.edu for details. However, users may print, download or email articles for individual use.

ISSN 2325-4009 (Print); ISSN 2325-4017 (Online) 